\title{
Enseñando democracia: normativa, realidad y propuestas en torno a la educación para la ciudadanía en el Perú
}

\section{Teaching democracy: normative, reality and proposals related to education for citizenship in Peru}

RENATO CONSTANTINO*

Resumen: El presente artículo apunta a revisar las bases ético-políticas de la educación para la ciudadanía. A partir del análisis de la normativa peruana se desprende la necesidad de que la escuela forme ciudadanos. Luego, se confronta esta normativa con la realidad de la escuela peruana. Se analizan también algunos casos de éxito y, a partir de esto, se formulan propuestas que posibiliten el desarrollo de una verdadera ciudadanía en nuestro país.

Palabras clave: educación en el Perú - educación para la ciudadanía educación cívica - democracia -condiciones para la democracia discriminación en el Perú - derecho a la educación

Summary: This article aims to review the ethical and political basis of education for citizenship. From the analysis of Peruvian normative it infers the necessity that school produces citizens. Then, it confronts these normative with the reality of Peruvian school. It also analyses some successful cases, and from this, it formulates proposals made to facilitate the development of a real citizenship in our country.

Keywords: education in Peru - education for citizenship - civic education democracy - conditions for democracy - discrimination in Peru - right to education

CONTENIDO: INTRODUCCIÓN.- I. ALGUNOS PUNTOS SUELTOS SOBRE LA EDUCACIÓN.- II. ¿PARA QUÉ ENSEÑAR EDUCACIÓN PARA LA CIUDADANÍA?.- II.1. ¿Y A QUÉ CIUDADANÍA ASPIRAMOS?.- II.2. ¿CÓMO LLEGAR A UNA CIUDADANÍA PLENA?.- II.3. ¿ME PUEDO NEGAR?.III. MARCO CONSTITUCIONAL Y EXPERIENCIA COMPARADA.- III.1. MARCO NORMATIVO PERUANO.- III.2. INSTRUMENTOS INTERNACIONALES.IV. REALIDAD DE LA ESCUELA PERUANA.- IV.1. LAS CONCLUSIONES Y RECOMENDACIONES DE LA CVR.- IV.2. PLAN CURRICULAR NACIONAL.IV.3. LA REALIDAD DE LA ESCUELA PÚBLICA.- V. ESPERANZA.V.1. ¿CÓMO SE DEBE ENSEÑAR?.- V.2. LOS ABOGADOS... ¿AYUDAMOS?.VI. ¿OASIS O ESPEJISMO? LA REALIDAD DEL COLEGIO FEY ALEGRÍA 43-LA SALLE DE VENTANILLA.- VIII. CONCLUSIONES.- VIII. (TRISTE) COLOFÓN.

* Alumno de la Facultad de Derecho de la Pontificia Universidad Católica del Perú. El ensayo es ganador del Concurso de Investigación Jurídica sobre Responsabilidad Social en Derecho 2011. 
Una buena conducta que consistía en acusar, en obedecer, en no correr y en no gritar, en estarse medio amodorrado sobre la banca del pupitre, estudiando idiotamente una pesadísima lección de geología [...]

José DIEZ CANSECO, Repartición de premios

\section{INTRODUCCIÓN}

Basta repasar algunas pocas narraciones para darnos cuenta de cómo históricamente la escuela peruana no ha sido un espacio de construcción de ciudadanía sino un espacio de reproducción de diversas taras que nos aquejan como sociedad. Sea el autoritarismo ${ }^{1}$, el clasismo ${ }^{2}$ o la corrupción ${ }^{3}$, la escuela no cumple la misión de formar ciudadanos. Simplemente conserva y prolonga nuestros problemas como sociedad.

La Comisión de la Verdad y Reconciliación (CVR) ha anotado tal problema como una de las condiciones que permitió que Sendero Luminoso pudiese expandirse rápidamente. Así pues, la ideología senderista fue transmitida «utilizando los viejos marcos pedagógicos autoritarios» ${ }^{4}$.

Es así que, de forma tardía, hemos notado algo que ya anunciaba Aristóteles y es que la educación forma el «carácter peculiar» ${ }^{5}$ que la sociedad requiere. Y una sociedad democrática necesita una educación democrática que forme ciudadanos que vivan los principios y valores que esta representa. Dentro de este orden de ideas, el presente trabajo busca analizar la formación ciudadana a la luz del artículo 14 de la Constitución y su plasmación (o la falta de esta) en la realidad.

\section{ALGUNOS PUNTOS SUELTOS SOBRE LA EDUCACIÓN}

Es necesario aclarar en principio qué entendemos por educación. Decía Walzer, parafraseando a Aristóteles, que «el propósito de la educación es reproducir en cada generación el «tipo de carácter» que habrá de mantener la Constitución» ${ }^{6}$. Las escuelas son un espacio (intermedio entre la familia y la sociedad) que proporciona un contexto para «el desarrollo de la comprensión crítica y la producción y la reproducción de la crítica social» ${ }^{7}$. Y es que no se puede entender la educación como

1 Ver, por ejemplo, La ciudad y los perros de Mario Vargas Llosa.

2 Como puede verse, por ejemplo, en Paco Yunque de César Vallejo.

3 Ver El cumpleaños del director de Antonio Gálvez Ronceros.

4 Comisión de LA Verdad y Reconciliación. Hatun Willakuy. Lima: Fondo Editorial de la Pontificia Universidad Católica del Perú, 2004, p. 458. En adelante, Hatun Willakuy.

5 ARIStÓteles. Política. Edición de Antonio Gómez Robledo. México D.F.:UNAM,1963, p. 236, 1337a.

6 WALZER, Michael. Las esferas de la justicia. Una defensa del pluralismo y la igualdad. Traducción de Heriberto Rubio. México D.F.: Fondo de Cultura Económica,2001,p. 208.

7 L. cit. 
un proceso meramente informativo sino precisamente más bien como un proceso formativo del cual la reflexión y el debate forman parte importante.

Para mejorar la comprensión de esto último es necesario acudir a las bases lingüísticas de la palabra «educar». Nos señala Teresa Arrieta que:

[...] la palabra educación se deriva de una raíz latina. Pero según sea la raíz que se elija el significado es absolutamente diferente. La palabra educare significa «entrenar», equipar al estudiante con una habilidad particular, mientras que la palabra educere tiene un significado diferente: «conducir hacia delante», «guiar hacia fuera» ${ }^{8}$.

Creo que es necesario acoger el segundo criterio de manera general y también de forma particular para la enseñanza de la educación para la ciudadanía. Y es que esta no puede darse como un cúmulo de información sino que se debe acompañar de vivencias, de comparación, de diálogo y debate. Y es a partir de eso que el educando, el futuro ciudadano, se formará. Conociendo sus derechos, aprenderá a respetar los de los otros como norma de convivencia, por poner un ejemplo bastante básico. Es un proceso de descubrimiento y crecimiento personal que repercute de manera beneficiosa para toda la comunidad.

También me parece importante resaltar que la educación básica (y, por ende, la educación para la ciudadanía) se otorga —o debe otorgarsede forma igualitaria, dado que no puede depender de la condición económica de los padres. Asimismo,los alumnos deben compartir «algo parecido a un mismo nivel» ${ }^{9}$.

La educación no es un proceso aislado. Vive dentro de una sociedad particular buscando fines específicos. Por tanto, es necesario tener claro qué fines se buscan y cómo se concretan (o si acaso se concretan) en el caso de la escuela peruana en lo referente a la educación para la ciudadanía.

\section{II. ¿PARA QUÉ ENSEÑAR EDUCACIÓN PARA LA CIUDADANÍA?}

No es fácil determinar por qué o para qué se enseña educación para la democracia. Si bien no existe (y está bien que no exista) un consenso definitivo sobre la democracia como el mejor sistema de gobierno, es bastante claro que sus principios (como la decisión de la mayoría, el respeto de las minorías, la posibilidad del disenso y la exigibilidad de ciertos derechos sociales en nombre de la dignidad humana) resultan claros para una gran mayoría de personas.

8 ARRIETA, Teresa. «Educación, tolerancia e identidad».En Alegría, Ciro \& otros (eds.).Tolerancia: ética y política. Lima: Fondo Editorial de la Pontificia Universidad Católica del Perú, 2011, p. 265.

9 WALZER, Michael. Ob. cit.,p.214. 
Estos valores se encuentran consagrados en la actualidad en la Constitución. Y es que, como bien señala Zagrebelsky, hoy en día se le encarga a la Constitución

[...] no la tarea de establecer directamente un proyecto predeterminado de vida en común, sino la de realizar las condiciones de posibilidad de la misma. Desde la Constitución, como plataforma de partida que representa la garantía de legitimidad para cada uno de los sectores sociales, puede comenzar la competición para imprimir al Estado una orientación de uno u otro signo, en el ámbito de las posibilidades ofrecidas por el compromiso constituciona ${ }^{10}$.

En tanto la Constitución tiene esta función, no puede omitir funciones educativas. Y es que la norma fundamental debe posibilitar la convivencia social. Esto lo señala Häberle al hablar de los fines educativos de la Constitución, los cuales tienen como tarea constituirse como «pedazos de la vida pública ${ }^{11}$. La educación tiene el deber de posibilitar, como la Constitución, la vida en común, y debe servir para evitar el socavamiento del sistema pluralista ${ }^{12}$. Como señala Zagrebelsky, ante la posibilidad de la eliminación del pluralismo del sistema democrático «debe valer la intransigencia» ${ }^{13}$. Y por tanto es válido enseñar educación para la ciudadanía para preservar la propia democracia. No por salvarla sin motivo, sino para asegurar la pervivencia del pluralismo.

Así es que existe la necesidad de ver qué valores dentro de un sistema democrático se deben enseñar. Häberle señala al respecto que:

Los fines educativos y los valores orientadores tienen una función específica como texto constitucional en sentido amplio, pues se trata de elementos formadores de consenso en el Estado constitucional y constituyen un pedazo de su identidad cultural y su vida pública. Son fines de la educación, por ejemplo, la tolerancia y la dignidad humana (o también «la imagen del ser humano»), la legalidad, la honestidad y la aceptación de la responsabilidad, la apertura hacia el mundo y el sentido del deber ${ }^{14}$.

Por tanto, podemos señalar que hay una serie de valores (Häberle los denomina fines) que es necesario inculcar a los futuros ciudadanos.

10 ZAGReBelsky, Gustavo. El derecho dúctil. Ley, derechos, justicia. Madrid: Trotta, 2009, p. 13.

11 HÄBERLE, Peter. El Estado constitucional. Lima: Fondo Editorial de la Pontificia Universidad Católica del Perú e Instituto de Investigaciones Jurídicas de la Universidad Nacional Autónoma de México, 2003, p. 187.

12 Habría que tener cuidado con lo que Carbonell denomina "constitucionalismo conservador» que es cuando la Constitución consagra ciertas discriminaciones. No es objetivo de este trabajo discutir qué ocurre en tales casos pero es importante abrir el debate sobre tal posibilidad. Ver CARBONELL, Miguel. «Neoconstitucionalismo y derechos fundamentales en América Latina: apuntes para una discusión».

Pensamiento Constitucional. XIV,14 (2010), pp. 21-23.

13 ZAGREBELSKY, Gustavo. Ob. cit., p. 15.

14 HÄBERLE, Peter. Ob. cit., pp.187-188. Las cursivas son nuestras. 
Como explicaremos más adelante, esto no debe ser visto como una imposición o un adoctrinamiento sino más bien como un «florecimiento» o «crecimiento» personal que, de forma mayeútica, concluye en la necesidad de ciertos valores para la convivencia a pesar de las diferencias.

\section{II.1. ¿Y a qué ciudadanía aspiramos?}

Ante lo dicho, es necesario aclarar a qué ciudadanía aspiramos y por qué. Existen básicamente dos modelos de ciudadanía. Habermas los describe así:

En lafilosofía del derecho compiten entre sí dos interpretaciones contrarias de esta ciudadanía activa. En la tradición liberal del derecho natural que procede de Locke cristalizó una comprensión individualistainstrumentalista del papel del ciudadano; y en la tradición republicana de teoría del Estado que se remonta a Aristóteles, una comprensión comunitarista-ética ${ }^{15}$.

Según Habermas, el modelo liberal de ciudadanía se centra en «los derechos individuales y en el trato igual». Así pues, la participación política tiene un «significado enteramente instrumental» ${ }^{16}$. En cambio, en el modelo republicano se «define la participación en el autogobierno como esencia de la libertad, como parte de lo que hay que asegurar. Ello es [...] un componente esencial de la condición de ciudadano» Esto se debe a que se considera que «la plena participación en el autogobierno [...] es capaz, por lo menos a veces, de conducir a la formación de un consenso dominante, en el que uno se puede identificar con los demás ${ }^{17}$.

Habermas elige el segundo modelo porque «la autonomía política es un fin en sí que nadie puede realizar por sí solo, es decir, persiguiendo privadamente sus propios intereses sino que solo puede realizarse por todos en común por la vía de una praxis intersubjetivamente compartida ${ }^{18}$.

Considero que es innegable que en nuestro país se debe aspirar a lograr una ciudadanía de modelo republicano. En un país con tantos problemas de corrupción, se vuelve imperativo que los ciudadanos participen activamente en el debate público. Me parece muy importante rescatar que, si bien el liberalismo evita que el Estado señale una concepción de vida buena privada para los ciudadanos, esto debe ser superado en el espacio público, donde la Constitución sí puede señalar ciertos valores o principios orientadores de la acción pública. 


\section{II.2.¿Cómo llegar a una ciudadanía plena?}

Resulta evidente que la ciudadanía no puede ser impuesta. $\mathrm{O}$, cuando menos, queda claro que hacerlo tendría algo de totalitario. Así pues, se debe buscar otra vía. Bajo esta perspectiva, considero que son la costumbre y la educación los medios más adecuados. Dice Habermas al respecto:

El modelo republicano de la ciudadanía nos recuerda que las instituciones de la libertad, aseguradas en términos de derecho constitucional, tendrán o no valor, conforme a lo que de ellas haga una población acostumbrada a la libertad, acostumbrada a ejercitarse en la perspectiva de primera persona del plural de la práctica de la autodeterminación. El papel del ciudadano institucionalizado jurídicamente ha de quedar inserto en el contexto de una cultura política habituada al ejercicio de las libertades ${ }^{19}$.

No se puede imponer la democracia ni se puede enseñar la democracia desde el autoritarismo. La educación para la democracia tiene que ser necesariamente democrática. Centrándonos nuevamente en la Constitución, es necesario señalar, siguiendo a Häberle, lo siguiente:

Los objetivos como la tolerancia, la democracia, la dignidad humana, la reconciliación de los pueblos o el «espíritu de la democracia», son directivas abiertas para un proceso en el que siempre debe ser posible un entendimiento mutuo y siempre renovado entre las generaciones: ila educación no es una calle de sentido único! ${ }^{20}$.

La Constitución nos da pautas abiertas sobre las cuales discutir y debatir. Y es que la Carta Magna no puede ser un documento escrito en piedra, inmutable. De ninguna manera: tiene que estar en contacto con la población, con la ciudadanía y con los futuros ciudadanos. Debe dar pautas y recibir interpretaciones. Estas pautas (llamadas fines educativos por Häberle) «son en mucho un proyecto anticipado del ser humano, que habrá de vivir y configurar la Constitución en el porvenir. Así vista, la Constitución se reencuentra en los fines educativos. iSu presente se encuentra con su futuro en forma pedagógica! ${ }^{21}$.

Esta discusión no es simple. Es compleja y extenuante. Anuncia futuras y complejas batallas jurídicas y políticas. Pero estas deberán respetar el mínimo marco constitucional que permite el pluralismo. Así, por ejemplo, señala Dionisio Llamazares:

¿Cómo puede estar ausente la reflexión sobre espacios de convivencia como la familia y sobre sus distintos tipos posibles, contando con el 
dato sociológico y el jurídico? ¿Cómo puede faltar la reflexión sobre la obligatoriedad de la ley vigente aunque se esté en desacuerdo con su contenido y sobre las relaciones de la ley con la conciencia? ¿Cómo puede estar ausente la reflexión sobre las relaciones entre jóvenes del mismo o distinto sexo, sean solo de amistad o sexuales y sus consecuencias? ¿Cómo puede estar ausente la reflexión, habida cuenta del dato sociológico y del dato jurídico, sobre los distintos modelos posibles de convivencia en pareja, heterosexual u homosexual, formalizada jurídicamente, civil o religiosamente, o como pura convivencia de hecho? iCómo puede estar ausente la reflexión sobre las relaciones entre padres e hijos o entre profesores y alumnos? ¿Cómo puede faltar reflexión sobre nuestros deberes de solidaridad con los otros? ¿Cómo puede faltar la reflexión sobre la búsqueda de la felicidad de cada uno que tiene sus límites infranqueables en la felicidad de los demás o sobre las coordenadas que no puede sobrepasar en ningún caso la competitividad con los otros? ¿Cómo puede faltar la reflexión sobre la armonización del principio de igualdad de oportunidades y la especial atención que merecen los sectores más vulnerables, desvalidos o menesterosos? ¿Es posible todo esto sin una reflexión a fondo sobre los distintos sistemas de producción y de organización social? ?2

\section{II.3. ¿Me puedo negar?}

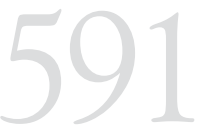

ENSEÑANDO

DEMOCRACIA:

NORMATIVA,

REALIDAD Y

PROPUESTAS

EN TORNO A LA

EDUCACIÓN PARA

LA CIUDADANÍA

EN EL PERÚ

TEACHING

DEMOCRACY:

NORMATIVE,

REALITY AND

PROPOSALS

RELATED TO

EDUCATION FOR

CITIZENSHIP IN

PERU

Existen dos clases de objeciones a la educación para la ciudadanía. La primera proviene de una concepción del Estado como un ente axiológicamente vacío. La segunda, en cambio, parte de la posibilidad de imponer la moral privada a la moral pública constitucional. Procedo a exponer ambas objeciones

A través de una concepción radical del liberalismo, se ha llegado a la conclusión de la neutralidad estatal con respecto a todo valor. Así, el Estado se convierte en un vacío axiológico sobre el cual se intentan construir algunos arreglos que permitan la convivencia. Quienes defienden esta posición aducen que el deber de llevar alguna asignatura sería un deber «de tipo paternalista o perfeccionista» ${ }^{23}$. Consideran que la formación de buenos ciudadanos «no ha de ser una misión de una disciplina escolar que se presenta al mismo tiempo como asignatura ordinaria y como empresa de adoctrinamiento o catequesis en los secretos de algún credo o cosmovisión, sea de orden religioso o secular» ${ }^{24}$. Consideran que la neutralidad «es el respeto hacia todas las cosmovisiones o doctrinas comprehensivas lo que impide que

22 llamazares Fernández, Dionisio. Educación para la ciudadanía democrática y objeción de conciencia. Madrid: Dykinson, 2010, pp. 112-113. Las cursivas son nuestras.

23 PRIETO SANCHís, Luis. «Educación para la ciudadanía y objeción de conciencia (Comentario crítico de la jurisprudencia del Tribunal Supremo)».Persona y Derecho, 60 (2009), pp. 209-240, p. 237.

24 lbídem, pp. 223-224. 
ninguna de ellas (incluida la nuestra) pueda ser objeto de exposiciones adoctrinadoras o apologéticas en el marco de una asignatura» ${ }^{25}$.

Esta visión yerra en una definición. Sí, el Estado no puede intervenir y hacer apología de alguna religión o cosmovisión para el ámbito privado. Es decir, no puede imponer modelos a seguir de vida buena. No obstante, sí puede, y está en la obligación de hacerlo, definir qué mínimos se necesita para la vida pública: la ciudadanía. El Estado, a diferencia de lo que creen quienes argumentan a favor de esta corriente, no es neutral en cuestión de valores. Tiene y defiende ciertos valores que le son consustanciales para la supervivencia de una sociedad plural. Señala adecuadamente Llamazares:

El Estado no es indiferente ni puede ser neutral con respecto a los valores comunes [principios y valores dela Constitución], ni puede ser neutral con respecto al compromiso de respetar el derecho a la diferencia [...] pero sí debe serlo con respecto a los valores diferenciales en cuanto tales: convicciones en el sentido del TEDH [Tribunal Europeo de Derechos Humanos], religiosas y no religiosas, étnicas, de género o culturales, vividas y sentidas como parte de la propia identidad, individual o colectiva, siempre que esos valores no entren en contradicción con los valores comunes ${ }^{26}$.

La otra objeción parte más bien desde ciertos grupos conservadores que sienten problemas con diversos contenidos de la asignatura de educación para la ciudadanía, pues consideran que, como los padres que son, pueden educar a sus hijos según sus propios valores. La enseñanza de ciertos valores comunes que colisionen con sus valores propios les permitiría activar una objeción de conciencia.

Una característica propia de la democracia es la objeción de conciencia. Es la posibilidad de que el Derecho, en el desarrollo de una ley, «si la conjugación con otros valores en juego lo permite sin merma de la satisfacción del interés general [...] [deje] abierta la posibilidad de que la propia ley exima al destinatario de esa obligación o prohibición en los supuestos en los que genere una auténtica contradicción con la norma de conciencia» ${ }^{27}$.

Un ejemplo clásico de esto es la objeción de conciencia al servicio militar obligatorio. Quienes se negaban a prestar el servicio, podían realizar algún otro servicio civil sin sanción alguna ${ }^{28}$.

25 lbídem, p. 224.

26 Llamazares Fernández, Dionisio. Ob. cit., p. 127.

27 Ibídem, p. 160.

28 Caso establecido en el artículo 30,inciso 2 de la Constitución de España de 1978 que dice: «La Ley fijará las obligaciones militares de los españoles y regulará, con las debidas garantías, la objeción de conciencia, así como las demás causas de exención del servicio militar obligatorio, pudiendo imponer, en su caso, una prestación social sustitutoria». 
Si bien los padres pueden criar a sus hijos bajo sus propias creencias y convicciones morales, no pueden impedir que lleven un curso de educación para la ciudadanía en tanto que simplemente se enseña un marco mínimo de convivencia. Ello no sofoca ni anula la posibilidad de desarrollar una moral privada.

No obstante, es obvio que tal moral privada no puede entrar en contradicción con la moral pública, puesto que prevalece la última. Como señala Llamazares: «la contradicción exige que la moral privada ceda ante la moral pública, lo que vale también para esa moral como posible contenido de la enseñanza pública ${ }^{29}$.

Así, pues, vemos la importancia que tiene la formación de la ciudadanía dentro de una democracia, así como las formas que puede adoptar y la imposibilidad de su negación. Pasamos a ver la positivización de los conceptos tratados.

\section{MARCO CONSTITUCIONALYEXPERIENCIACOMPARADA}

\section{III.1. Marco normativo peruano}

El marco normativo peruano estaría definido por la Constitución, las leyes y los instrumentos internacionales. En este primer apartado analizaremos la Constitución, así como la interpretación constitucional.

El artículo pertinente es el 14 de la Constitución, que reza así:

La educación promueve elconocimiento, el aprendizaje y la práctica de las humanidades, la ciencia, la técnica, las artes, la educación física y el deporte.Prepara para la vida y el trabajo y fomenta la solidaridad.

Es deber del Estado promover el desarrollo científico y tecnológico del país.

La formación ética y cívica y la enseñanza de la Constitución y de los derechos humanos son obligatorias en todo el proceso educativo civil o militar. La educación religiosa se imparte con respeto a la libertad de las conciencias.

La enseñanza se imparte, en todos sus niveles, con sujeción a los principios constitucionales y a los fines de la correspondiente institución educativa.

Los medios de comunicación social deben colaborar con el Estado en la educación y en la formación moral y cultural ${ }^{30}$.

ENSEÑANDO

DEMOCRACIA:

NORMATIVA,

REALIDAD Y

PROPUESTAS

EN TORNO A LA

EDUCACIÓN PARA

LA CIUDADANÍA

EN EL PERÚ

TEACHING

DEMOCRACY:

NORMATIVE,

REALITY AND

PROPOSALS

RELATED TO

EDUCATION FOR CITIZENSHIP IN

PERU 
Rubio $^{31}$ señala como antecedentes el artículo 79 de la Constitución de 1933 que decía: «La educación moral y cívica del niño es obligatoria y se inspirará necesariamente en el engrandecimiento nacional y la solidaridad humana».

También señala como antecedente el artículo 22 de la Constitución de 1979, que decía lo siguiente:

La educación fomenta el conocimiento y la práctica de las humanidades, el arte la ciencia y la técnica. Promueve la integración nacional y latinoamericana; así como la solidaridad internacional.

La formación ética y cívica es obligatoria en todo el proceso educativo. La educación religiosa se imparte sin violar la libertad de conciencia. Es determinada libremente por los padres de familia.

La enseñanza sistemática de la Constitución y de los Derechos Humanos es obligatoria en todos los centros de educación civiles, militares y policiales en todos sus niveles ${ }^{32}$.

Vemos que la preocupación por la educación cívica o ética no es reciente. Y que esta no depende de valores morales particulares sino que se basa claramente en la Constitución y los derechos humanos.

En nuestro país, queda claro que lo expuesto en el capítulo anterior está plenamente vigente. El Tribunal Constitucional ha señalado que los fines constitucionales del proceso educativo en nuestro país son:

a) Promover el desarrollo integral de la persona.

El proceso educativo debe contribuir a la plena formación intelectual, moral, psicológica y física de las personas.

b) Promover la preparación de la persona para la vida y el trabajo.

El objeto del proceso educativo es que la persona pueda insertarse plenamente en la sociedad, y que, por ende, pueda crecer y progresar como ser humano dentro del entorno en donde coexiste.

Asimismo, tiene como fin que el educando pueda desarrollar con inteligencia, conocimiento y habilidad suficiente, una determinada actividad generadora de un bien o servicio que coadyuve a su gratificación espiritual por lo realizado, y que le sirva como medio de sustento para la satisfacción de sus necesidades materiales. 
c) El desarrollo de la acción solidaria.

La solidaridad implica la creación de un nexo ético y común para las personas adscritas a un entorno social ${ }^{33}$.

No queda duda de que nuestra Constitución y nuestra historia constitucional han dado una gran importancia a la formación de ciudadanos. Si bien se debe tener claro que el Estado debe ser laico, no es un vacío axiológico sino que defiende distintos valores en el ámbito público necesarios para la convivencia en común. No es cuestión de defender la democracia per se sino por los valores que representa. Esto ha sido señalado también en la Ley General de Educación (ley 28044) en su artículo 9:

Artículo 9ํ.-- Fines de la educación peruana

Son fines de la educación peruana:

a) Formar personas capaces de lograr su realización ética, intelectual, artística, cultural, afectiva, física, espiritual y religiosa, promoviendo la formación y consolidación de su identidad y autoestima y su integración adecuada y crítica a la sociedad para el ejercicio de su ciudadanía en armonía con su entorno, así como el desarrollo de sus capacidades y habilidades para vincular su vida con el mundo del trabajo y para afrontar los incesantes cambios en la sociedad y el conocimiento.

b) Contribuir a formar una sociedad democrática, solidaria, justa, inclusiva, próspera, tolerante y forjadora de una cultura de paz que afirme la identidad nacional sustentada en la diversidad cultural, étnica y lingüística, supere la pobreza e impulse el desarrollo sostenible del país y fomente la integración latinoamericana teniendo en cuenta los retos de un mundo globalizado.

\section{III.2. Instrumentos internacionales}

La preocupación que hemos encontrado reflejada en nuestra experiencia constitucional y legal también la podemos encontrar en diferentes instrumentos internacionales. Citaremos tres instrumentos que rescatan la necesidad de que la educación persiga un objetivo que favorezca la democracia y el respeto por los derechos humanos. Todos tendrán fuerza interpretativa en nuestro país de acuerdo a la cuarta disposición final y transitoria.

ENSEÑANDO

DEMOCRACIA:

NORMATIVA,

REALIDAD Y

PROPUESTAS

EN TORNO A LA

EDUCACIÓN PARA

LA CIUDADANÍA

EN EL PERÚ

TEACHING

DEMOCRACY:

NORMATIVE,

REALITY AND

PROPOSALS

RELATED TO

EDUCATION FOR

CITIZENSHIP IN

PERU 
La Declaración Universal de los Derechos Humanos (DUDH) señala en su artículo 26.2:

La educación tendrá por objeto el pleno desarrollo de la personalidad humana y el fortalecimiento del respeto a los derechos humanos y a las libertades fundamentales; favorecerá la comprensión, la tolerancia y la amistad entre todas las naciones y todos los grupos étnicos o religiosos, y promoverá el desarrollo de las actividades de las Naciones Unidas para el mantenimiento de la paz $z^{34}$.

En el artículo 13.1 del Pacto Internacional de Derechos Económicos Sociales y Culturales (PIDESC), las partes acuerdan que:

[...] la educación debe orientarse hacia el pleno desarrollo de la personalidad humana y del sentido de su dignidad, y debe fortalecer el respeto por los derechos humanos y las libertades fundamentales. Convienen asimismo en que la educación debe capacitar a todas las personas para participar efectivamente en una sociedad libre, favorecer la comprensión, la tolerancia y la amistad entre todas las naciones y entre todos los grupos raciales, étnicos o religiosos, y promover las actividades de las Naciones Unidas en pro del mantenimiento de la paz.

Finalmente, la Convención sobre los Derechos del Niño dice en su artículo 29.1, literal d):

Preparar al niño para asumir una vida responsable en una sociedad libre, con espíritu de comprensión, paz, tolerancia, igualdad de los sexos y amistad entre todos los pueblos, grupos étnicos, nacionales y religiosos y personas de origen indígena $[\ldots]^{35}$.

Como podemos apreciar, en el mundo, la educación no es simplemente una capacitación laboral. Es un espacio de conocimiento, sí, pero también de desarrollo de valores que permitan una convivencia pacífica en igualdad desde las diferencias. Aceptar y vivir las diferencias es lo que posibilita realmente la democracia.

\section{IV.REALIDAD DE LA ESCUELA PERUANA}

Se levanta una gran interrogante cuando nos preguntamos si el mandato de la Constitución y de los tratados internacionales se cumple de manera efectiva en nuestro país en lo referente a la educación para la ciudadanía ${ }^{36}$. Para constatar esto, pasaremos a analizar dos fuentes básicas para el entendimiento de la educación para la ciudadanía en nuestro 
país: el Informe Final de la Comisión de la Verdad y Reconciliación y el Plan Curricular Nacional Actual.

\section{IV.1. Las conclusiones y recomendaciones de la CVR}

Como se mencionó anteriormente la CVR encuentra en la educación uno de los grandes factores que posibilitaron el conflicto. La educación había sido abandonada por el Estado y, a pesar de los esfuerzos modernizadores, no se pudo neutralizar «el predominio de pedagogías tradicionales autoritarias» ${ }^{37}$. De hecho, una de las respuestas al conflicto armado fue volver a la Instrucción Premilitar ${ }^{38}$, perpetuando las respuestas autoritarias al conflicto en el espacio escolar ${ }^{39}$.

La escuela no era un espacio que apreciase la diferencia. Más bien ha sido siempre en el Perú un espacio para la homogeneización ${ }^{40}$, que a su vez «reproducía desigualdades previas, exacerbando resentimientos y frustraciones que terminaron contribuyendo a la reproducción del ciclo de la violencia» ${ }^{41}$. Y acá vale la pena traer a colación la reflexión de Sandoval sobre los espacios en que se reproduce la violencia:

vemos que los proyectos autoritarios germinan con mayor eficacia en instituciones que no reconocen las diferencias - como es el caso de la escuela y el servicio militar obligatorio- y que por el contario se asientan en paradigmas de integración homogeneizadores que, llevados al extremo, no hacen más que expresar el desprecio y el racismo que usualmente se esconden bajo una máscara paternalista ${ }^{42}$.

La escuela no se logró librar de las grandes taras de la sociedad peruana como el racismo y la discriminación. Tal es la reflexión que nos deja el mencionado informe.

Para combatir estos problemas radicales de la educación nacional, varias de sus propuestas apuntan a:

buscar un consenso en torno a la promoción de valores democráticos, interiorizar la importancia de los derechos humanos, el respeto de las diferencias, la valoración del pluralismo y la diversidad cultural, la difusión de visiones del país actualizadas y que den cuenta de su complejidad, y el rechazo de la violencia como medio para resolver

37 Hatun Willakuy, p. 458.

38 Comisión dE LA VeRDAD y RECONCILIACIÓN. Informe final. Lima: CVR, 2003. Tomo III, p. 584. En adelante, Informe final.

39 Tal curso no fue asignado al Ministerio de Educación sino al de Defensa. Ver ibídem, p. 585.

40 Como bien señala Nelson Manrique: «Para los progresistas, en fin, se trataba de redimir al indio por medio de la educación. La «redención» del indio consistía en que este dejara de serlo. No eliminarlo física sino culturalmente. El etnocidio cultural». Ver MANRIQUE, Nelson. Enciclopedia Temática del Perú. Tomo VII: Sociedad. Lima: Empresa Editora El Comercio, 2004, p. 25.

41 Sandoval, Pablo. Educación, ciudadanía y violencia en el Perú: una lectura del informe de la CVR. Documento de Trabajo IEP 142. Lima: IEP, TAREA, p. 8.

42 Ibídem, p. 9.

ENSEÑANDO

DEMOCRACIA:

NORMATIVA,

REALIDADY

PROPUESTAS

EN TORNO A LA

EDUCACIÓN PARA

LA CIUDADANÍA

EN EL PERÚ

TEACHING

DEMOCRACY:

NORMATIVE,

REALITY AND

PROPOSALS

RELATED TO

EDUCATION FOR

CITIZENSHIP IN

PERU 
conflictos; también para elevar la calidad de la educación, para que satisfaga las expectativas de progreso y desarrollo de la población ${ }^{43}$.

El Informe Final de la CVR aporta varias conclusiones relativas a la educación. Para los fines de este trabajo solo tocaremos algunas de ellas ${ }^{44}$.

1. Poner énfasis en políticas educativas destinadas a la transformación de la escuela en un lugar donde se respete la condición humana del alumnado y se contribuya al desarrollo integral de su personalidad. Lograr una conciencia de paz y afirmar la educación como su instrumento ${ }^{45}$.

Resulta clara la importancia que el Informe Final de la CVR le otorga a la educación. La distingue claramente como el instrumento que puede posibilitar verdaderamente la paz en nuestro país.

2. Establecer un Plan de Estudios que estimule el conocimiento y oriente el saber hacia el bienestar para lograr una formación integral y alejamiento a la proclividad a la violencia; reformulación de visiones simplistas y distorsionadas de la historia y realidad peruana ${ }^{46}$.

La propuesta de la CVR apunta a desterrar visiones fatalistas o derrotistas de la historia peruana. Es lamentablemente cierto que muchas veces la historia se cuenta como un sinnúmero de oportunidades perdidas que parecen apuntar a la incapacidad de autogobernarnos. Asimismo, llama a desterrar las visiones simplistas del materialismo.

3. Promoción de una educación en el respeto a las diferencias étnicas y culturales. Adaptar la escuela en todos sus aspectos a la diversidad étnico-lingüística, cultural y geográfica del país ${ }^{47}$

Se recomienda promover la enseñanza intercultural y en el idioma materno para lograr que la escuela se adapte a todos los ámbitos de nuestro país.

4. Reforzar instancias de participación y democratización de la escuela $^{48}$

Es claro que no se puede enseñar la democracia desde el autoritarismo. Es por eso que la CVR reclama por un manejo mucho más democrático de la escuela peruana. Así, llama a permitir la participación activa de los padres y de las autoridades locales en la escuela pública.

43 Informe final. Tomo IX, p. 111

44 Ibídem, pp. 134-138.

45 lbídem, p. 134.

46 L. cit.

47 Ibídem, p. 135.

48 Ibídem, p. 136. 
5. Disciplina ${ }^{49}$

Este apartado me parece muy importante. La disciplina en un ambiente democrático que debe fomentar la autonomía personal. No debe basarse ni en la amenaza ni en el castigo. LaCVR propone prohibir y sancionar todo castigo físico y trato humillante.

\section{IV.2. El Plan Curricular Nacional}

El Plan Curricular Nacional es el documento elaborado por el Ministerio de Educación que determina los contenidos curriculares de los cursos a dictar ${ }^{50}$. Estos son válidos (y de cierto modo obligatorios) para la educación pública y para la educación privada. El documento señalan los objetivos de la educación básica regular, entre los que destacan la interculturalidad, la democracia, la ética y la inclusión ${ }^{51}$.

Lo que sería la educación para la ciudadanía recibe el nombre de Formación Ciudadana y Cívica y tiene por finalidad «favorecer el desarrollo de procesos cognitivos y socio-afectivos en el estudiante, que orienten su conciencia y actuación cívico-ciudadana en un marco de conocimiento y respeto a las normas que rigen la convivencia y la afirmación de nuestra identidad de peruanos ${ }^{52}$. Señala como método para lograr esto «la participación activa y responsable del estudiante en el abordaje y solución de asuntos y problemas propios de sus entornos, a partir del diálogo, el debate, la reflexión, la clarificación de valores y su puesta en práctica mediante la ejecución de proyectos». Asimismo, recalca la necesidad de que este aprendizaje se genere en democracia $^{53}$. Se aprecia un plan coherente con las recomendaciones de la CVR. Es necesario destacar que las dos grandes áreas de aprendizaje son Identidad e Interculturalidad y Sociedad Democrática ${ }^{54}$. También debemos rescatar que, en quinto grado de secundaria, se habla del conflicto armado interno, de verdad, justicia y memoria colectiva, así como de reconciliación naciona ${ }^{55}$.

Cabe preguntarse: ise aplica a cabalidad este plan?, icómo se aplica? Y finalmente: ifunciona?, itiene efectos?

49 L. cit.

50 El documento se titula Diseño Curricular Nacional de la Educación Básica Regular y se encuentra disponible en la página web del Ministerio de Educación. Fue aprobado por resolución ministerial 0440-2008-ED.

51 lbídem, p. 17.

52 lbídem, p. 397.

53 L. cit.

54 lbídem, p. 398.

55 Ibídem, p. 408. 


\section{IV.3. La realidad de la escuela pública}

Es obvio que la educación para la ciudadanía en el Perú es un objetivo relativamente reciente a pesar de que el discurso político haya ido en otra dirección ${ }^{56}$. La educación para la ciudadanía (concebida como educación cívica) no ha tenido como objetivo la formación de ciudadanos que valoren la pluralidad. Más bien, ha tendido a buscar la homogenización o la asimilación de aquellos a los que se considera distintos ${ }^{57}$. Así pues, diseños curriculares y planes de educación se tienen que enfrentar de manera abierta y complicada a estructuras y discursos sociales que no fomentan realmente la ciudadanía.

Existen varios trabajos realizados sobre la escuela peruana. Suelen coincidir en puntos importantes que traeremos a colación. En principio, debemos analizar la dinámica de la socialización escolar. En ella encontramos dos tipos de espacios de socialización: uno oficial y uno alternativo ${ }^{58}$. El espacio oficial premia a aquellos que cumplen con las metas que propone el espacio. Es decir, la calificación: la nota aprobatoria y el desaprobado o «jalado». En el espacio alternativo, en cambio, se premia al «vivo», al que puede evitar las reglas sin ser descubierto, al fuerte, al que se impone. Señala Callirgos que tal es la imagen del criollo popular, «el «achorado», el «vivo», astuto, el que no se va a dejar engañar ni burlar ni insultar, el que sabe pelear o por lo menos amedrentar a sus posibles rivales, sabe jugar fútbol u otros deportes «para hombres», sabe poner apodos, bromear, conquistar a las chicas, el que se atreve a hacer aquello que está prohibido» ${ }^{59}$.

Así pues, finalmente se termina castigando a los que no logran alcanzar tal estatus. Se marca una jerarquía basada en diferentes características, donde ciertas características, como los rasgos fuertemente andinos, los defectos físicos, el hablar con acento andino o «motoso», la menor habilidad deportiva, la pobreza más acentuada o la timidez se convierten en cargas para los alumnos dentro del proceso de socialización escolar. Se convierten en los «puntas», los «mongos», los «lornas» ${ }^{60}$.

¿Por qué se aspira a tal modelo? ¿Por qué el modelo oficial sucumbe ante el modelo alternativo? La respuesta es trágica. Las recompensas del modelo oficial son nulas. En nuestro país, la escuela pública ya no es un espacio que permita la movilidad social. Por tanto, es probable que tanto

56 Ver las referencias al marco normativo peruano explicado líneas arriba.

57 CALliRgos, Juan Carlos. La discriminación en la socialización escolar. Separata. Lima: Fondo Editorial de la Pontificia Universidad Católica del Perú, p. 1. Disponible en http://www.cholonautas. edu.pe/modulo/upload/Callirgos.pdf.

58 Utilizo acá la denominación de Callirgos (ibídem,p. 2). Uccelli, en cambio, denomina a estos espacios de socialización espacio formal - espacio informal. Véase UcCELLI, Francesca. «Autoridad y liderazgos entre los alumnos». Disponible en http://www.cholonautas.edu.pe/modulo/upload/ Uccelli.pdf.

59 CALLIRGos, Juan Carlos. Ob. cit., p. 2.

60 Ibídem, pp. 3-4. 
el buen alumno como el mal alumno tengan las mismas oportunidades laborales en la vida.

El problema es estructural, queda claro. No obstante, los profesores juegan un rol enorme dentro de este problema, pues son las primeras figuras de autoridad. Muchas veces, el inicio de la falla parte de estas autoridades que no ofrecen verdaderos incentivos «oficiales». Y es que - y este es el meollo del asunto- la escuela no es un espacio democrático y, por tanto, difícilmente puede ofrecer incentivos para la democracia. De hecho, los docentes suelen tener incentivos para no ser «cercanos» puesto que esto es mal visto ${ }^{61}$. Así, «los maestros, de una manera u otra, también se encuentran en medio de dos tendencias: representar a la escuela «oficial' y sus mandatos «democráticos»; y sucumbir en la tentación del autoritarismo; o intentar acercarse de manera abierta a los alumnos, y ser mal visto desde lo «oficial»» ${ }^{62}$.

Por otra parte, los conflictos suelen sublimarse, callarse o expresarse violentamente, puesto que no existen canales efectivos que permitan la resolución de conflictos. Uccelli, al respecto, señala lo siguiente:

Ante situaciones de molestia de los alumnos o conflicto explícito entre alumnos y docentes, el diálogo no aparece como un mecanismo de resolución de los problemas; por el contrario, parece ser que la ausencia de diálogo resuelve o, mejor dicho, no resuelve el conflicto. La indiferencia de los alumnos expresada en las entrevistas con frases tales como «lo ignoro», «me volteo», «me quedo callada» son evidencia de las reacciones del alumno ante actitudes o situaciones de molestia con el profesor ${ }^{63}$.

Paso a describir un ejemplo descrito por Callirgos y luego hablaré de otro que fue noticia hace un par de meses en nuestro país.

Callirgos relata el siguiente caso: un chico de 14 o 15 años y uno de aproximadamente 11 son llevados a la dirección. El menor de ellos ha sido golpeado por otros chicos de su edad y sus ojos reflejan lágrimas recientes. El mayor es acusado de haber iniciado el pleito. Este cuenta que cargó al niño a su salón cuando un grupo golpeó al menor en la espalda e intentó quitarle los pantalones. El director resuelve el conflicto pidiéndole que se den la mano y los envía a sus salones ${ }^{64}$.

61 Uccelli también destaca el papel de los alumnos en estos incentivos al señalar que «el comportamiento de los alumnos parece exigir y avalar el autoritarismo como componente necesario de la autoridad. Esto se muestra en el rechazo y la intolerancia frente al docente permisivo, incapaz de mantener el orden en el aula, mientras el profesor estricto y autoritario es más respetado como tal. El alumno legitima este tipo de autoridad rechazando al profesor permisivo y respetando al autoritario". Ver UCCELLI, Francesca. Ob. cit., p. 14. Vemos pues que tanto el espacio oficial como el alternativo envían incentivos al profesor para no ser realmente democrático en su actuación.

62 CAlliRgos, Juan Carlos. Ob. cit., p. 6.

63 UCCELLI, Francesca. Ob. cit., p. 8.

64 CalliRgos, Juan Carlos. Ob. cit., p. 8.

ENSEÑANDO

DEMOCRACIA:

NORMATIVA,

REALIDAD Y

PROPUESTAS

EN TORNO A LA

EDUCACIÓN PARA

LA CIUDADANÍA

EN EL PERÚ

TEACHING

DEMOCRACY:

NORMATIVE,

REALITY AND

PROPOSALS

RELATED TO

EDUCATION FOR

CITIZENSHIP IN

PERU 
Como vemos, quien infringe la norma no recibe castigo. El director avala el comportamiento abusivo del chico mayor. Si legitimamos tales actitudes como normales, simplemente desterramos a la democracia de la socialización escolar. No importa qué se predique en las aulas, si acaso ello se hace de forma correcta ${ }^{65}$.

Clinton Maylle es un alumno del Colegio Micaela Bastidas en San Juan de Lurigancho (distrito de la periferia urbanizada de Lima Norte). Sus rasgos físicos son claramente andinos: su rostro, sus pómulos, su nariz. Si acaso quedase duda, la entonación que tiene al hablar lo delata ${ }^{66}$. Una persona, un compañero de aula que fue golpeado salvajemente por sus compañeros hasta quedar postrado en un hospital de Lima. Golpeado cruelmente por ser distinto. $O$ más que por ser distinto ${ }^{67}$, por no querer ser igual a todo el resto ${ }^{68}$. Con posterioridad, uno de los señalados como agresor relató que, de forma previa a la golpiza, agresor y agredido habían intercambiado insultos de tinte racista ${ }^{69}$. Si en el lugar donde debemos empezar la enseñanza de la ciudadanía vemos que campea el autoritarismo, el miedo, el recelo y la intolerancia..., ipodemos hablar de la posibilidad de educar ciudadanos en las aulas? iEs posible cambiar las cosas o perpetuaremos a la escuela como una reproductora de desigualdades y discriminaciones?

\section{V.ESPERANZA}

En esta sección paso a describir algunos leves intentos que se han probado para cambiar esta realidad y para que se pueda realmente formar ciudadanos. Son varios intentos, algo dispersos pero que vale la pena rescatar. No es sencillo intentarlo, no es sencillo ir contra la corriente y rebelarse frente a la estructura que parece imponerse a nosotros. Pero vale la pena.

65 El caso no deja de recordarme, con obvias diferencias, a la acusación que le hace Alberto Fernández, el «Poeta», a Gamboa sobre el asesinato de el «Esclavo», cuyo victimario sería el «Jaguar». El "Jaguar» se salva. Fernández es amenazado con la expulsión de seguir con la acusación y a Gamboa se lo envía de servicio a la sierra peruana a manera de castigo por no callar. A casi 50 años de la publicación de tal novela, parece que los mismos miedos que atormentaban a los personajes de Vargas Llosa atormentan hoy a los alumnos de la escuela peruana.

66 Hay que tener cuidado de pensar que el desprecio hacia lo marcadamente andino refleja una ventaja para los alumnos caucásicos. Señala Callirgos que la raza blanca suele ser relacionada con la delicadeza. En las mujeres suele ser una ventaja, pero no para los hombres, que preferirán más bien tener rasgos físicos que los ubiquen «al medio», ser un «berraco» (nombre que se le da a los cerdos mestizos, de raza indefinida, usualmente más resistentes a las enfermedades). Ver CALLIRGos, Juan Carlos. Ob. cit., p. 16.

67 Cabe anotar que en el Perú, el racismo contra las personas de rasgos andinos no se focaliza en una minoría sino más bien en un grupo humano bastante significativo de la población peruana.

68 Ver el caso en Peru 21. «Escolar queda parapléjico tras golpiza». Disponible en http://peru21.pe/ noticia/656724/escolar-queda-paraplegico-golpiza. Consulta: lunes 5 de setiembre de 2011.

69 Ver El Comercio. "Presunto agresor de escolar que quedó parapléjico dice que no tiene culpa de nada». Disponible en http://elcomercio.pe/lima/659023/noticia-presunto-agresor-escolar-que-quedoparaplejico-dice-que-no-tiene-culpa-nada. Consulta: lunes 5 de setiembre de 2011. 


\section{V.1.¿Cómo se debe enseñar?}

Hay que señalar que otro de los problemas en la educación para la ciudadanía es el método de enseñanza. De acuerdo con Magendzo ${ }^{70}$, existen tres modalidades de enseñanza de la ciudadanía: la patriarcal, la científico-racional, y la democrática.

La primera modalidad tiene como objetivo asegurar que los alumnos ocupen sus respectivos lugares en la dinámica de la división social del trabajo. Así pues, la democracia pasa a ser solo una careta formal de la dominación de los grupos dominantes. El «interés nacional» solo favorece a quienes tienen el poder para la interpretación ventajosa. La formación política se limita a fomentar el cumplimiento de las normas. Se busca fomentar cierto patriotismo. Dentro de esta concepción, la educación religiosa, como corrector moral, juega un papel importantísimo ${ }^{71}$.

La segunda modalidad, en cambio, se basa en una concepción política donde el mercado es el agente que regula las instituciones sociales. Así, asume preponderancia la preparación científica y se deja de lado el cultivo de las ciencias sociales o de las humanidades. La educación cívica se minimiza o se convierte en orientación vocacional o en preparación para la vida laboral. Los contenidos políticos son mínimos.

La tercera modalidad es la democrática. Surge en Suecia como respuesta a las doctrinas totalitarias. La educación ciudadana busca preparar ciudadanos que puedan construir una mejor sociedad. Así pues, se entiende a la escuela como un espacio que permite la realización de ciertos ideales políticos como la democracia y la equidad. Para esto,la participación constituye un elemento esencial en esta concepción. El alumno debe conocer la sociedad y saber que tiene la posibilidad de influir positivamente en ella, sea a través de las actividades políticas o los voluntariados. Esta concepción, asimismo, viene acompañada de un fuerte contenidocrítico, puestoque se entiende que ningún conocimiento (ni estructura legislativa) es inmune a los cuestionamientos.

En nuestro país han sido los dos primeros modelos descritos los que han sido más utilizados. Tradicionalmente, en la educación cívica se ha privilegiado el civismo, vinculado tradicionalmente al amor a la patria y

70 MAgendzo, Abraham. Formación ciudadana. Bogotá: Cooperativa Editorial Magisterio, 2004, pp. 31-37.

71 Debo manifestar mi oposición a la presencia del curso de Educación Religiosa en las escuelas públicas peruanas. No solo es atentatorio contra los principios del Estado laico sino que también resulta contraproducente con la idea de formar ciudadanos. Solamente se pueden formar ciudadanos bajo la idea de una «moral pública». Imponer una «moral privada» por el simple hecho de ser mayoritaria y compartir algunos valores con la moral pública constitucional debilita la idea de ciudadanía puesto que, como sabemos, la religión se basa en dogmas absolutos libres de cuestionamiento, mientras que la ciudadanía es un constante ejercicio de crítica, cuestionamiento y participación. De una opinión similar es GARCíA FIGUEROA, Adolfo. «La nueva asignatura de Educación para la Ciudadanía y los Derechos Humanos. Un test para la racionalidad del sistema educativo». Sistema, 199 (2007), pp. $61-78$. 
la emulación de los héroes ${ }^{72}$. Esta visión no es exclusiva de los peruanos, sino que es una práctica común en toda América Latina ${ }^{73}$. Así, pues, se puede identificar la presencia de dicho modelo en el «paporreteo» de ciertos elementos de civismo (la bandera, la escarapela, los símbolos patrios) o en «la memorización de artículos de la Constitución [...] y el conocimiento sólo formal de la estructura del Estado» ${ }^{74}$.

El segundo modelo es bastante novedoso. No se suele aplicar en la escuela pública sino en un nuevo tipo de escuela que surge durante el gobierno de Fujimori: el colegio preuniversitario. Estos colegios desechan ciertos contenidos «tradicionales» como la Educación Física o la Educación Cívica para privilegiar la preparación para el examen de ingreso a la Universidad. La educación cívica no aparece en los contenidos curriculares ${ }^{75}$ y si acaso se hace mención a los «valores» se hace solo con referencia a aquellos orientados al trabajo y al éxito personal ${ }^{76}$. Y esto se da precisamente porque se viene asentando entre la clase media peruana un individualismo en el cual el bienestar personal se ve totalmente desligado del espacio público. El ingreso a la universidad no es visto como un espacio de crecimiento personal sino

72 VEGA, Rudecindo. «Educación Cívica para educar a la ciudadanía». En ASOCIACIÓN CIVIL TRANSPARENCIA. Democracia, ciudadanía y educación cívica en la escuela peruana. Lima: Asociación Civil Transparencia, 2000, pp. 123-124.

73 Al respecto, ver CAJAS, Juan y Norma UBALDI. «Cultura, política e ideología: reconstrucción histórica del debate sobre la educación cívica en América Latina». Disponible en http://www.ife.org.mx/ documentos/DECEYEC/vgn_ivestigacion/cultura_politica_e_ideologia.htm.

Señalan los autores: «En América Latina cada país hizo suyo determinado discurso educativo, a partir del cual se dio forma a una peculiar nación. En términos generales, el concepto de «educación cívica» ha estado asociado a la idea de generar cierto "espíritu cívico" dentro de los ciudadanos. Dicho espíritu cívico es, sucintamente, en términos antropológicos una cuestión de lealtades o al menos un sentido de pertenencia identitaria con una sociedad en particular, en nuestro caso: la chilena, costarricense, paraguaya, colombiana, estadounidense, nicaragüense o uruguaya; cada una de ellas con una singular forma de evolución y desarrollo sociocultural, que se prolonga hasta nuestros días".

74 MUJICA, Rosa María. "Metodología y técnicas de enseñanza". En Asociación CIVIL TRANSPARENCIA. Ob. cit., p. 85.

75 La página web del Colegio Trilce señala lo siguiente:

«Nuestros alumnos reciben una sólida formación académica, a través del desarrollo de las siguientes áreas:

Matemática: Aritmética, Álgebra, Geometría, Trigonometría [...].

Comunicación: Lenguaje, Literatura, Plan Lector, Redacción y Argumentación.

Ciencias: Física: Química, Anatomía, Biología.

Humanidades: Historia Universal, Historia del Perú, Geografía, Economía, Actualidad Nacional e Internacional.

Aptitud: Razonamiento Matemático, Razonamiento Verbal [...].

Arte: Dibujo, Pintura, Danza.

Educación Física.

Computación: laboratorios con multimedia y acceso a internet. Convenio Cibertec».

Como vemos, no aparece el curso de Educación Cívica por ningún lado. Información disponible en http://www.trilce.edu.pe/colegios/surco/secundaria.htm. Consulta: 6 de setiembre de 2011.

76 El Colegio Pamer señala en el rubro de «Tutoría, Psicología y Valores» lo siguiente:

"Contamos con el mejor Sistema de Tutoría Personalizada a través del cual, todos los alumnos tendrán un seguimiento individual de rendimiento académico, puntualidad y asistencia; y un constante estímulo para el desarrollo de su personalidad.

El tutor exige todos los días a cada alumno para que no decaiga en el esfuerzo permanente que debe realizar, lo motiva siempre para que no pierda el ánimo e interés en el estudio y lo orienta fomentando en él hábitos y actitudes que lo llevarán a desarrollar al máximo sus facultades, convirtiéndose en un estudiante de éxito". Información disponible en http://www.pamer.edu.pe/secundaria/secundaria. php? modulo=secundaria\&idpagina $=4$. Consulta: 6 de setiembre de 2011 . 
de una profesionalización que permite ingresar en mejores condiciones al mercado laboral.

La tercera modalidad no ha sido muy aplicada en nuestro país ${ }^{77}$. No obstante queremos ofrecer algunas líneas sobre su desarrollo. Es muy importante conocer qué técnicas se pueden aplicar para la educación para la ciudadanía. No son realmente un misterio. Parten de una visión democrática, crítica y participativa de los alumnos. Gustavo Cruz, con referencia a La Casa de Cartón señala algunas técnicas:

«las asambleas (de aula, de ciclo, cultural o general): en las que se trabajan noticias, acuerdos, quejas, sugerencias

-El trabajo de noticias

-Las responsabilidades en el aula

-Las consignas

-El Consejo Estudiantil

-Los retos personales y grupales

-Las salidas, paseos y campamentos

-La proyección social ${ }^{78}$.

Dentro de lo mencionado, me parece muy rescatable la idea del Consejo Estudiantil. Posibilita el empoderamiento de los estudiantes. Les permite viabilizar proyectos, les da iniciativa, los educa en la participación, la representación y la rendición de cuentas. La experiencia ha sido adoptada por diversos centros educativos particulares. En los centros educativos nacionales hay una experiencia equiparable: los municipios escolares. Allí también se vive lo que describí en el caso de los Consejos Estudiantiles pues, como señala María Teresa Mosqueira, un«niño que opina, participa y se organiza, expresará sus sentimientos e ideas, respetará y valorará la opinión de los demás; convivirá democráticamente con sus semejantes; y desarrollará valores solidarios y sentido de permanencia colectiva» ${ }^{79}$.

Otra forma que me parece resaltante es la educación a través del arte. Es importante porque le permite al estudiante reconocerse a sí mismo, pero también ponerse en el lugar del otro, posibilitando la valoración y el respeto por el otro, consiguiendo así un mejor resultado ${ }^{80}$.

77 Se citan algunos colegios en ASOCIACIÓN CIVIL TRANSPARENCIA. Ob. cit., como por ejemplo el CIFO (Colegio Isabel Flores de Oliva) y La Casa de Cartón. También podemos mencionar a Los Reyes Rojos, creado por Constantino Carvallo.

78 Cruz, Gustavo. "Currículo educativo y nuevas propuestas». En ASOCIACIÓN CIVIL TranSPARENCIA. Ob. cit., pp. 52-53.

79 MOSQUEIRA, María Teresa. «Los municipios escolares: una experiencia de ciudadanía y educación en valores». En AsOCIACIÓN CIVIL TRANSPARENCIA. Ob. cit., p. 153.

80 MEsía, Ericka \& otros. Educando con arte. Una manera lúdica de enseñar derechos humanos (Guía para docentes). Lima: Proyecto financiado por el Rectorado de la Pontificia Universidad Católica del Perú/administrado por la Dirección Académica de Investigaciones (DAI) de la PUCP/avalado por el Instituto de Derechos Humanos y Democracia (IDEHPUCP), 2005, pp. 11-12. Al respecto, cabe señalar lo mencionado aquí y decir lo siguiente: «El arte juega un papel importante. La facilidad

ENSEÑANDO

DEMOCRACIA:

NORMATIVA,

REALIDAD Y

PROPUESTAS

EN TORNO A LA

EDUCACIÓN PARA

LA CIUDADANÍA

EN EL PERÚ

TEACHING

DEMOCRACY:

NORMATIVE,

REALITY AND

PROPOSALS

RELATED TO

EDUCATION FOR

CITIZENSHIP IN

PERU 


\section{V.2. Los abogados... ¿ayudamos?}

Desde el derecho también se han realizado esfuerzos. No obstante, creo que no se ha reflexionado mucho sobre la importancia que tiene la educación para la ciudadanía como verdadera posibilidad de democracia. Algunos esfuerzos han sido más una explicación formal de los derechos ${ }^{81}$, lo cual solo nos conduce, como hemos visto, a la memorización inútil y a la desvalorización de la importancia de nuestros derechos. Y es que el Derecho, como parte de la educación para la ciudadanía, así como también la Ética, deben ser conocimiento, reflexión y aplicación a situaciones concretas. Si la educación para la ciudadanía se convierte en puro conocimiento sin correlato práctico, se convierte en un ejercicio infructuoso.

Pero sí existen esfuerzos que apuntan hacia lo que buscamos. En la Facultad de Derecho de la PUCP, existen espacios de educación legal que buscan fortalecer la conciencia ciudadana y dar a niños y ciudadanos conciencia sobre sus propios derechos. Es un espacio que permite a estudiantes, niños y ciudadanos reflexionar sobre sus propios derechos $^{82}$.

\section{VI. ¿OASIS O ESPEJISMO? LA REALIDAD DEL COLEGIO FE Y ALEGRÍA 43-LA SALLE DE VENTANILLA}

No me es fácil determinar si existen esperanzas o posibilidades reales de cambio. Para corroborar esto, decidí aplicar una encuesta en un salón de quinto de secundaria del Institución Educativa Fe y Alegría 43-La Salle en el distrito de Ventanilla. Entrevisté a varios alumnos sobre tres temas que me parecieron interesantes: homosexualidad, igualdad de género y percepción sobre la democracia. Esta encuesta se realizó a alumnos del quinto grado de secundaria. La respondieron 13 mujeres y 18 hombres entre los 15 y 17 años de edad. Las preguntas apuntaban a presentar ciertos dilemas morales para forzar una reflexión sincera sobre las preguntas escapando de clichés o respuestas deshonestas.

del arte para propiciar una identificación con el otro, que está representado en la obra de arte, nos permite esta sensibilización de la que hablamos: mirar y reconocerse con el otro"(ibídem, p. 12).

81 Podemos considerar como ejemplo de esto a CHANAMÉ OrBE, Raúl. Aprendamos la Constitución. Lima: Editorial San Marcos, 1998.

82 ORTIZ SÁNCHEZ, Iván. «Proyección y Responsabilidad Social en las Facultades de Derecho».Derecho PUCP, 65 (2010), pp. 268-269. Sobre los inicios de la Proyección Social en la Facultad de Derecho de la PUCP, revisar ZOLEZZI IBÁRCENA, Lorenzo. «La responsabilidad social en la formación de los abogados». Derecho PUCP, 65 (2010), especialmente pp. 252-254. 


\begin{tabular}{|c|c|c|c|c|c|}
\hline \multicolumn{6}{|c|}{ ¿Puede un homosexual ser profesor de nido? } \\
\hline \multicolumn{2}{|c|}{$\begin{array}{c}\text { Respuesta } \\
\text { no discriminatoria }\end{array}$} & \multicolumn{2}{|c|}{$\begin{array}{c}\text { Respuesta no discriminatoria } \\
\text { pero prejuiciosa }\end{array}$} & \multicolumn{2}{|c|}{$\begin{array}{c}\text { Respuesta } \\
\text { discriminatoria }\end{array}$} \\
\hline Hombres & $11,11 \%$ & Hombres & $27,77 \%$ & Hombres & $61,11 \%$ \\
\hline Mujeres & $38,46 \%$ & Mujeres & $0 \%$ & Mujeres & $61,53 \%$ \\
\hline Total & $22,58 \%$ & Total & $16,13 \%$ & Total & $61,29 \%$ \\
\hline \multicolumn{6}{|c|}{ ¿Puede un homosexual estar en el ejército? } \\
\hline \multicolumn{2}{|c|}{ Respuesta no discriminatoria } & \multicolumn{2}{|c|}{$\begin{array}{c}\text { Respuesta no discriminatoria } \\
\text { pero prejuiciosa }\end{array}$} & \multicolumn{2}{|c|}{ Respuesta discriminatoria } \\
\hline Hombres & $33,33 \%$ & Hombres & $11,11 \%$ & Hombres & $55,55 \%$ \\
\hline Mujeres & $46,15 \%$ & Mujeres & $0 \%$ & Mujeres & $53,84 \%$ \\
\hline Total & $38,71 \%$ & Total & $6,45 \%$ & Total & $54,84 \%$ \\
\hline \multicolumn{6}{|c|}{ ¿Puede una mujer ser presidenta? } \\
\hline \multicolumn{3}{|c|}{ Respuesta igualitaria } & \multicolumn{3}{|c|}{ Respuesta no igualitaria } \\
\hline Hombres & & $94,44 \%$ & Hombres & & \\
\hline Mujeres & & $100 \%$ & Mujeres & & \\
\hline Total & & $96,77 \%$ & Total & & \\
\hline \multicolumn{6}{|c|}{ Opine sobre la siguiente frase: «No necesitamos democracia, al fin y al cabo, no da de comer» } \\
\hline \multicolumn{3}{|c|}{ Favorable a la democracia } & \multicolumn{3}{|c|}{ Contrario a la democracia } \\
\hline Hombres & & $100 \%$ & Hombres & & $0 \%$ \\
\hline Mujeres & & $100 \%$ & Mujeres & & $0 \%$ \\
\hline Total & & $100 \%$ & Total & & $0 \%$ \\
\hline
\end{tabular}

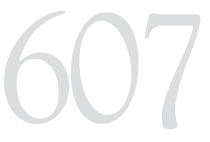

ENSEÑANDO

DEMOCRACIA:

NORMATIVA,

REALIDAD Y

PROPUESTAS

EN TORNO A LA

EDUCACIÓN PARA

LA CIUDADANÍA

EN EL PERÚ

TEACHING

DEMOCRACY:

NORMATIVE,

REALITY AND

PROPOSALS

RELATED TO

EDUCATION FOR

CITIZENSHIP IN

PERU

Fue complicado planear la encuesta. No obstante, los resultados parecen ser regulares en el caso de discriminación y bastante alentadores sobre la percepción de la democracia. En el caso de discriminación hacia homosexuales, los resultados se parecen bastante a los de la última encuesta realizada en nuestro país al respecto: el porcentaje que rechazaría que un profesor homosexual dicte en un nido es de $61 \%{ }^{83}$. La otra respuesta también discrimina en un porcentaje similar. No obstante, hay que discernir al momento de ver la respuesta no discriminadora. Existen quienes no discriminan pero tienen respuestas prejuiciosas. Así pues, en el primer caso un chico responde: «Sí, porque normalmente suelen tener una tendencia a ser más delicados, sutiles, amigables para

83 Ver El Comercio. «La tolerancia a la homosexualidad se abre paso en nuestro país». 23 de agosto del 2009. Disponible en http://elcomercio.pe/lima/331940/noticia-tolerancia-homosexualidad-se-abrepaso-nuestro-pais. Consulta: 8 de setiembre de 2011. 
niños pero para los que entienden lo toman como enfermos» (hombre, 17 años).

Vemos que la respuesta no discrimina directamente pero deja entrever posiciones terribles. Casi como una primera acepción de tolerancia. La homosexualidad es mala pero se debe tolerar. Hay que ser cuidadoso con tal acepción. No discrimina directamente pero lleva dentro de sí el germen de la intolerancia.

En el caso de la segunda pregunta, la mayoría presumía la debilidad de los homosexuales. De hecho, las respuestas no discriminatorias prejuiciosas lo revelan:

«Creo que sí porque a pesar de todo es un ser humano con la capacidad de autodesarrollarse y crecer» (mujer, 16 años).

Si vemos algunas de las respuestas y las cotejamos con la tercera pregunta encontramos algunas cosas sorprendentes. El poder (la presidencia) ya no sería un espacio exclusivamente masculino. No obstante, en la visión de muchos, las Fuerzas Armadas sí lo son. Varias de las respuestas discriminatorias de las propias mujeres afirman que ese espacio no podría ser ocupado por nadie con características que ellas ven como «femeninas».

«No porque si es un homosexual no va a soportar tanto como lo haría un verdadero hombre como fuerza, voz, postura, etcétera.» (mujer, 16 años).

Pero existen respuestas verdaderamente alentadoras. Exponemos dos de ellas, sobre las dos primeras preguntas:

«Sí, porque la homosexualidad no es una discapacidad ni tampoco una enfermedad y además debemos darles una oportunidad ya que muchas veces nosotros se las negamos» (mujer, 16 años).

«Sí, porque su orientación sexual no influye en su rendimiento, además no se puede negar nada a ninguna persona que esté dispuesto a servir a la patria» (mujer, 16 años).

Creo que los resultados no se diferencian mucho de los generales según la encuesta mencionada. Pero hay que tomar en cuenta la argumentación. Se necesita aún mucha más evidencia empírica para afirmar o negar algo en cuanto a la tolerancia a la homosexualidad.

Mucho más alentadores son los resultados sobre democracia. En su totalidad los alumnos responden de forma positiva hacia la democracia otorgándole un valor inherente y no solo funcional. El 100\% de los alumnos la defiende a pesar de que posiblemente no le ven beneficios en el plazo inmediato. $Y$ es que saben que: 
«con la democracia el pueblo es el que manda y queramos o no nos organizamos mejor» (hombre, 16 años).

El resultado me parece muy alentador. Es muy relevante cuando el apoyo a la democracia en el Perú es solo del $61 \%{ }^{84}$.

ENSEÑANDO

DEMOCRACIA:

NORMATIVA,

Ahora bien, ipor qué estos resultados difieren a lo constatado en el capítulo IV?

Por lo conversado con el director, padres de familia y alumnos, es el reconocimiento y la utilidad de la escuela. La escuela es un símbolo de progreso que no sirve en el Perú. Pero esta escuela sí funciona. Muchos salen de allí ya con un oficio. Algunos consiguen becas especiales y siguen estudios universitarios. Si la escuela funciona, el alumno tiene los incentivos para esforzarse dentro del marco «oficial». Asimismo, los profesores hacen un gran esfuerzo para que ciertos valores inspiren la actuación de los estudiantes. Vemos pues que la valoración por la ciudadanía parece crecer cuando se empodera a los estudiantes y se les muestra la escuela como un espacio de desarrollo y cuando la educación que reciben es un ejercicio de democracia en contenidos y actitudes.

\section{VII.CONCLUSIONES}

REALIDAD Y

PROPUESTAS

EN TORNO A LA

EDUCACIÓN PARA

LA CIUDADANÍA

EN EL PERÚ

TEACHING

DEMOCRACY:

NORMATIVE,

REALITY AND

PROPOSALS

RELATED TO

EDUCATION FOR

CITIZENSHIP IN

PERU

Como mencioné líneas arriba, la educación no es un fenómeno aislado. Es un fenómeno social que responde a ciertos valores éticos reflejados en la Constitución. La construcción de la ciudadanía depende de la educación. Una educación que no debe reproducir esquemas autoritarios o discriminadores y que debe otorgarle al estudiante la oportunidad de crecer como persona. Tal desarrollo necesita basarse en el reconocimiento la auto-conciencia valorativa, el reconocimiento del otro y, finalmente, el empoderamiento. De lo analizado, es claro que las experiencias que empoderan a los estudiantes, sea valorativa o políticamente, les permiten ejercer un mayor nivel de ciudadanía. Y es que la ciudadanía es esencialmente eso: reconocimiento del otro como igual y empoderamiento personal y colectivo para cambiar la sociedad.

Considero que necesitamos, por tanto, cuatro cosas como mínimo

- Una educación de calidad que ofrezca verdaderas oportunidades de crecimiento personal y movilidad social

- Una comunidad educativa verdaderamente democrática donde prime el respeto 
- Reflexión profunda sobre los derechos y deberes de las personas (como niños, como estudiantes y como ciudadanos)

- Experiencias de empoderamiento estudiantil, como los Consejos Estudiantiles o los Municipios Escolares, que permitan el desarrollo de políticas participativas dentro de los centros de estudios

Obviamente existen incompatibilidades con lo que existe hoy. Algunos cambios son de actitudes o personas. Pero otros son estructurales y requieren de legislación adecuada y voluntad política para ser llevados a cabo. Entendamos que la escuela es un servicio público que necesita ser regulado de forma mucho más plena para asegurar una verdadera ciudadanía.

\section{VIII. (TRISTE) COLOFÓN}

Lamentablemente, en el camino de vuelta a casa luego de realizadas las encuestas en Ventanilla, me crucé con la Universidad César Vallejo, una institución que lucra con los sueños de miles de jóvenes, con sus ganas de convertirse en profesionales. Uno de sus murales rezaba «Al que quiere triunfar no le importa si la vida es injusta». Poco podemos progresar realmente si nos negamos la posibilidad de enfrentar las injusticias. Se hace más que necesario el reconocer las posibilidades de cambio que trae consigo la educación y no permitir que se convierta en triste alienación. 